\title{
Identity of Tarennine with Dihydroelaeocarpidine
}

The alkaloid tarennine, isolated from Tarenna bipindensis (K. Schum, Bremerkamp, Rubiaceae, Index Kewensis, Suppl. No. 9, 1938), has been described in a French patent ${ }^{1}$, where mp's of $125-126^{\circ} \mathrm{C}$ for the free base and $294-295^{\circ} \mathrm{C}$ (in our hands $264-269^{\circ} \mathrm{C}$ ) for the men ${ }^{3}$. We have also repeated the synthesis of GRIBBLE ${ }^{4}$ and found both preparations to be identical with our tarennine base (mp, IR- and mass-spectrum). Tarennine is therefore identical with dihydroelaeocarpidine, and it is proposed that the former name should be dropped.

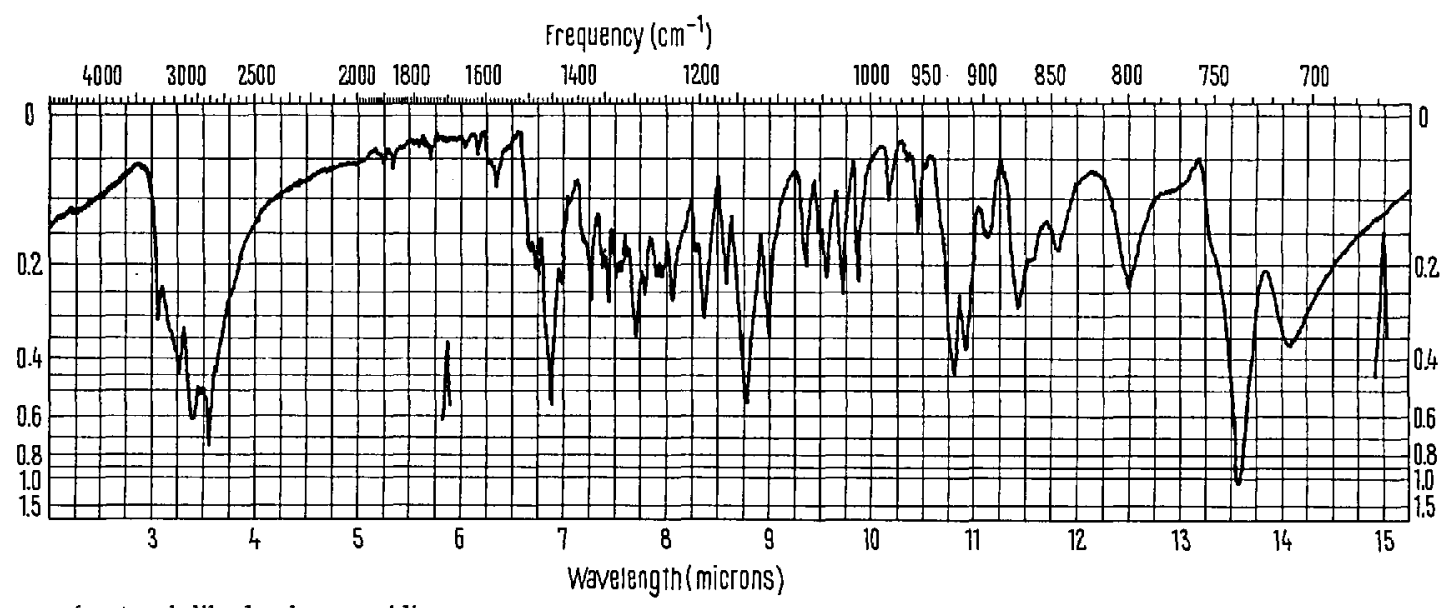

IR-spectrum of natural dihydroelaeocarpidine.

dihydrochloride are given. Also a chlorine analysis for the dihydrochloride $(19.98 \%)$ and $\mathrm{Br}$ - and J-values for the methobromide and the methiodide respectively are mentioned. Data for the UV-spectrum are given, and an IR-spectrum is reproduced in extenso.

In completion of the above hydrochloride analysis, the following values have been obtained for this salt: $\mathrm{C}=59.50,59.32 ; \mathrm{H}=7.28,7.42 ; \mathrm{N}=12.23,12.20 ;$ $\mathrm{O}$ (quant.) $=0.85,0.66$. Without taking into account the very low oxygen values, these analyses agree with the formula $\mathrm{C}_{17} \mathrm{H}_{23} \mathrm{~N}_{3} \cdot 2 \mathrm{HCl}$ for tarennine hydrochloride $(\mathrm{C}=59.64 ; \mathrm{H}=7.31 ; \mathrm{N}=12.31 ; \mathrm{Cl}=20.75)$. The mass-spectrum was measured with a spectrometer CEC 21-110 (Dupont Instrument Prod.) $70 \mathrm{eV}$. The m.w. was found to be 269.1892 . The fragmentation clearly indicated fragments of an indolic system: $83(52 \%), 97(7.5 \%), 144$ $(7.2 \%), 171(56 \%), 184 / 185(10 \%), 196(32 \%), 197$ $(100 \%=$ base peak), $198(20 \%), 225(2.5 \%), 239(2.5 \%)$. $269(60 \%), 270(12 \%)$. With the exception of the peak at $M+197$, all figures are identical with the ones published for dihydroelaeocarpidine.

Dihydroelaeocarpidine is a hydrogenation product of claeocarpidine, an alkaloid obtained from Elaeocarpus archboldianus by JoHns et al. ${ }^{2}$.<smiles></smiles>

Elaeocarpidine<smiles>c1ccc2c3c([nH]c2c1)C(CCN1CCCC1)NCC3</smiles>

Dihydroelaeocarpidine
Elaeocarpidine possesses 2 asymmetric carbon atoms, but it is claimed to be optically inactive. By hydrogenation one asymmetric carbon atom is lost, and dihydroelaeocarpidine has only one asymmetric centre. Tarennine base, within the limits of error, was also optically inactive.

(土) Dihydroelaeocarpidine has been synthesized twice ${ }^{3,4}$, and we had at our disposal a synthetic specj-
It is interesting to note that derivatives of elaeocarpidine occur not only in the small family of the Elaeocarpaceae, but also in Rubiaceae ${ }^{5}$.

Zusammenjassung. Das in der Rubiaceae Tarenna bipindensis K. Schum aufgefundene Tarennin besitzt die Bruttoformel $\mathrm{C}_{17} \mathrm{H}_{29} \mathrm{~N}_{3}$ und ist identisch mit Dihydroelaeocarpidin. Zur Identifizierung dienten IR-, Massenspektrographie und Smp.

J. R. BoIssier ${ }^{\mathrm{a}}$, G. COMBES ${ }^{6}$, A. H, EFFLER ${ }^{7}, K, K_{L I N G A}{ }^{7}$ and E. SCHLITTLER?

Department of Pharmacology, Ecole de Médecine,

University of Paris and Department of Pharmacology,

University of Heidelberg, Hauptstrasse 47/51,

D-6900 Heidelberg (Germany), 5 February 1971.

1 J. R. Boissier and G. Combes, French Patent 1.391764, Cl. A, $61 \mathrm{~K}-\mathrm{C} \mathrm{07g}$, March 12, 1965, see Chem. Abstr. 62, 15.996 (1965).

2 S. R. Johns, J. A. Lamberton and A. A. Sioumis, Chem. Commun. $1968,410$.

3 J. Harley-Mason and C. G. Taylor, Chem. Commun. 1969, 281. We are grateful to Dr. HARLEY-MASON for an authentic specimen of dihydroelaeocarpidine.

4 G. W. Gribile, J. org. Chem. 35, 1944 (1970).

5 We are indebted to Miss M. Wemme and Mr. T. H. ERLenMaier of the Chemistry Department of Heidelberg University for the mass-spectra.

- Department of Pharmacology, Ecole de Médecine, University of Paris.

7 Department of Pharmacology, University of Heidelberg. 